$\xi=$

\title{
Conceptualisation and framework for developing an educational program for caregivers of the elderly
}

\author{
Joan.M.Kloppers *, Agnes Van Dyk \\ School of Public Health School of Medicine Faculty of Health Science The University of Namibia; Windhoek; Namibia \\ *Corresponding author E-mail: jkloppers@ unam.na
}

\begin{abstract}
Most frequently, elderly are cared for in institutions by lay people. This can result in poor quality of care and neglect of the elderly. These caregivers lack skills and knowledge in the delivering of care for the elderly. The aim of the study was to do a situational analysis of the experiences of the elderly as well as the caregivers in respect of caring for the elderly in old age homes. The objective of the study were to explore and describe the experiences of the caregivers and the elderly with respect to caring for the elderly and nursing care they receive. A qualitative, explorative, descriptive, contextual and phenomenological design was used to perform this study. Themes were identified, as for example interpersonal relationship and communication (positive as well as negative). A Lack of in-service training for caregivers was revealed, as well as a lack of caring procedures, policies and guidelines. Staff shortages, were also identified. Out of these findings a conceptual framework was developed.
\end{abstract}

Keywords: Elderly; Caregiver; Old Age Home; Programme; Evaluation

\section{Introduction}

According to Mouton, (1996) (in Masunga 2007) conceptualisation refers to both the clarification and the analysis of the key concepts in a study and to the way in which one's research is integrated into the body of existing theory and research. According to Mouton, (1996) in Masunga 2007) it also refers to the underlying theoretical framework that guides and directs this study.

From the results obtained by relating the experiences of the elderly and caregivers, concerning the care that is provided to them, the main themes and sub-themes were identified. A schematic representation of the elements of a practice theory, as described by Dickoff, James and Wiedenbach (1968), is indicated in figure 4.1: Reasoning Map. Main concepts were classified and organised systematically, within latter mentioned.

\subsection{Method}

The research design selected for this study was qualitative, explorative, descriptive, contextual and phenomenological designs. The study was conducted in four old age homes.

\subsection{Target Population}

The first target population group consisted of sixty four caregivers of the five old age homes. Twenty- six were identified for the sample and interviewed. The age range of caregivers were twenty to sixty three years. Most were female and only one male, was sampled. The $2^{\text {nd }}$ target group consisted of twenty nine elderly who participated. Twenty one were female and eight were men. Their ages ranged from sixty to ninety seven years. The elderly were residents in these old age homes for a duration of two months to twenty eight years.

\subsection{Conducting interviews}

Data for the situational analysis was collected from in-depth interviews held at the five old age homes in Windhoek, in the natural setting of the participants. In-depth interviews were held in order to understand the "emic" or insider view of a phenomenon, culture, social world or issue (Polit \& Beck, 2008). Dzija, Hernandz, Nardi, Theriault, \& Wynne, (2005) stated that if people are allowed to chat freely in a non-threatening environment, they tend to be more cooperative. Elderly and caregivers in the five old age homes were also interviewed in 2009.

Interviews were started by posing the following question to the elderly:

"Tell me about your experience of the caring that you receive from the caregivers". To the caregivers "Tell me about your experience of caring for the elderly in old age homes."

Notes taken were read to the participants to verify that they truly reflected what was said and to find out whether any additional information existed.

\subsection{Data analysis}

Data analysis commenced as soon as the researcher had listened to the opinions of participants. The data collected was unstructured, thus the eight steps of Tesch's approach of open coding (Tesch, 1995), was used to develop an organised system of data.

\subsection{Ethical consideration}

Approval to conduct the study was granted by the Research Ethics Committee of the University of Namibia. The Ministry of Health and Social Services granted permission for the old age home. The elderly and caregivers gave informed consent to participate in the 
study. The persons in charge of the old age homes also granted permission. All interviews were conducted on the basis of anonymity.

\subsection{Results of Interviews}

Three themes emerged out of various comments from participants. Main theme 1: Interpersonal Relationships with sub- themes of: character of participants; communication and language; perseverance; patience and respect were viewed as positive experiences. Negative experiences included stressful behaviour, temperament and confusion. Main theme 2: Basic physical care, with subthemes of personal hygiene; wound care; taking of medication; and nutrition and exercise. Main theme3: Managerial support with sub-themes of equipment; transport; lack of in-service training; and staff shortages.

\section{Conceptual framework}

A conceptual model can be defined as a set of highly abstract terms related to constructs that broadly explain phenomena of interest, express assumptions and reflect a philosophical framework (Burns \& Grove, 2005). This enables the researcher to link findings to the nursing body of knowledge.
According to Fawcett (1991) (in Burns \& Grove, 2005), an organised programme of research is important for building a body of knowledge related to the phenomena. While according to Woodgate (1999) (in Norlyk, 2010), the basis for the development of qualitative studies is more philosophical than theoretical.

The framework is derived deductively from the theory. For this study the conceptual framework of Dickoff et al. (1968) was chosen. The reasoning map will be discussed below.

\subsection{Reasoning map}

In terms of the reasoning map (see figure 4.1 below), the "agent "refers to the researcher with her scientific knowledge and skills who performs the activity. The "recipient" is the caregiver who needs to be empowered to give quality care to the elderly people. The "framework" is the context in which the activity is performed in the old age homes. "Terminus "refers to the end point of the activity. The end point is to have a competent caregiver with knowledge about the elderly and skills to perform activities. The "procedure" is the guiding processes, technique or protocol of the activity. The "dynamics "refers to the energy source that is needed for the activity, which is the relevant dimensions, realities and theories (Dickoff et al., 1968).

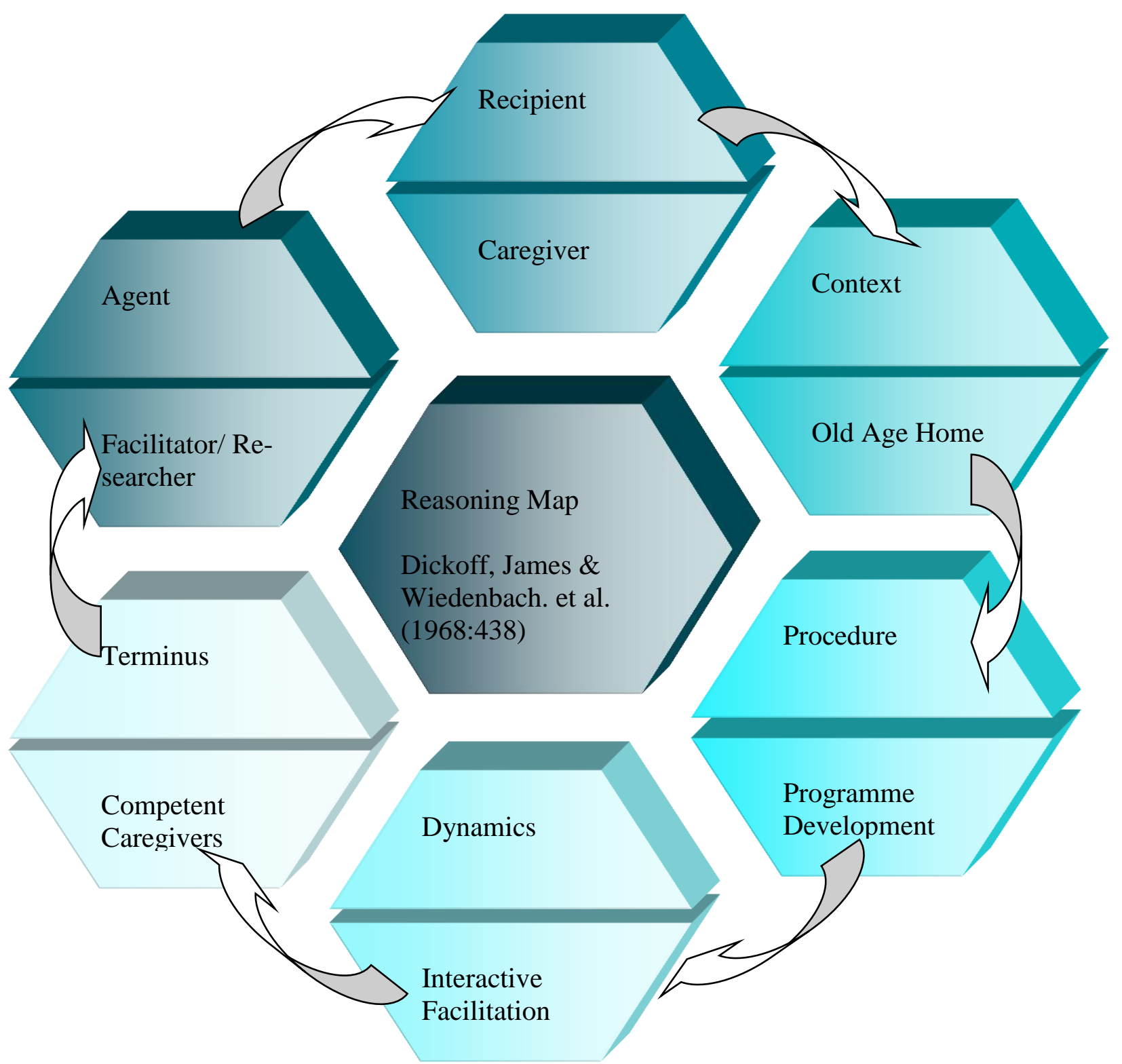

Fig. 2.1: Reasoning Map Source: Dickoff Et Al., 1968. 


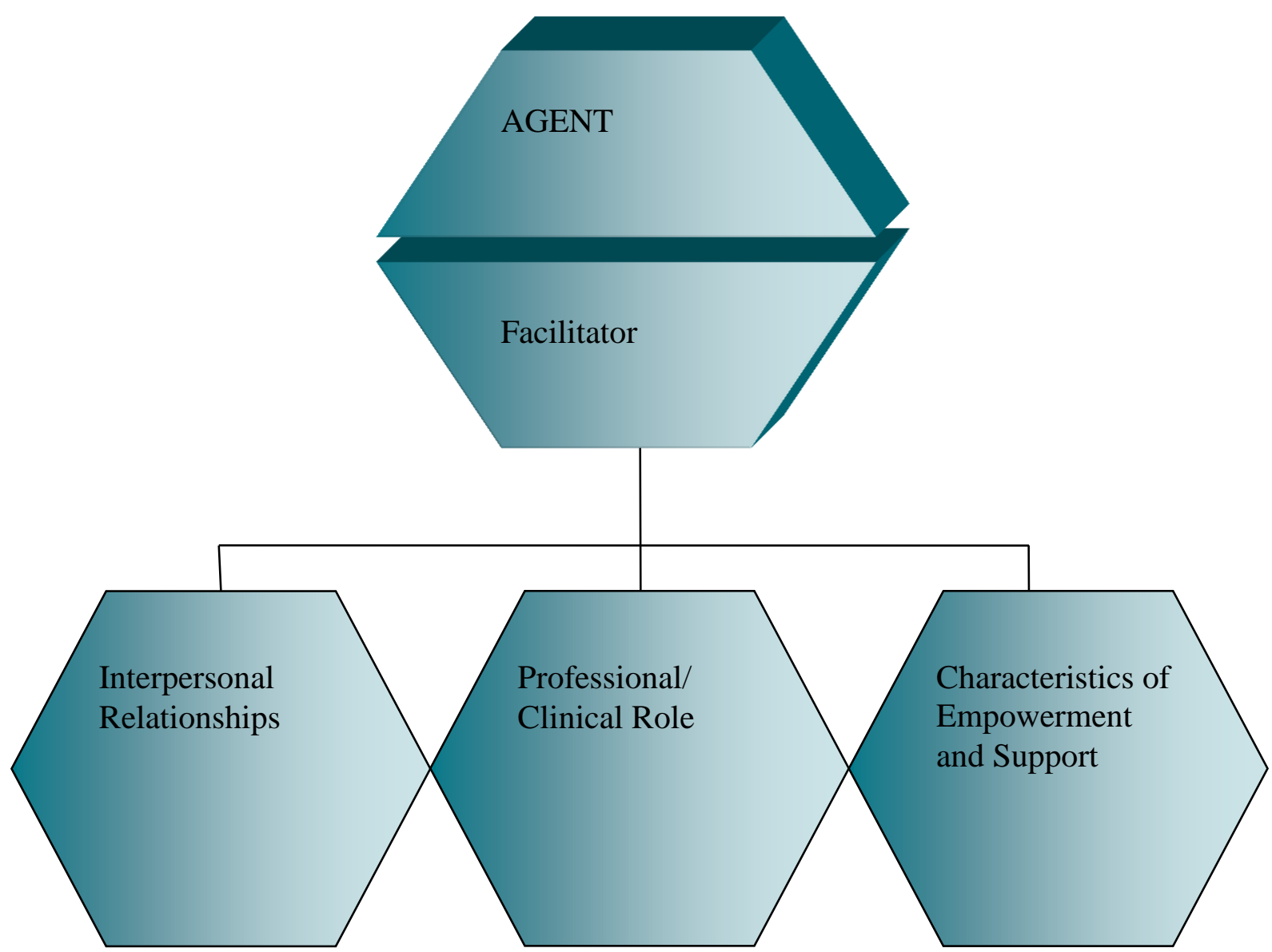

Fig. 2.2: The Agent: Facilitator (Researcher).

\subsubsection{Agent: facilitator (researcher)}

The agent is a researcher, lecturer, facilitator and community health nurse who lectures third-year students of the Comprehensive Diploma in Clinical Practice. Students are often assessed in old age homes, where they conduct physical assessments of the elderly.

According to Stanhope and Lancaster (2006), the community health nurse is equipped with leadership roles through applying the nursing process, as well as public health science, to the population at risk, for example the elderly in old age homes.

The agent must have the following characteristics:

Educational aptitude (particular skill)

Educational preparation for the community health nurse is based on a synthesis of current knowledge, nursing research, public health and other scientific disciplines. Additionally, the agent is required to perform the functions of a generalist and specialist and should possess clinical experience in interdisciplinary planning, organising, delivering and evaluation of services. Community empowerment and political and legislative activities should also be performed. The functions of professional nursing should also be performed and include assessing, diagnosing, conducting physical examinations, developing and implementing treatment plans for acute and chronic illnesses.

Clinical skills as a clinician

Community health nursing practice includes nursing directed at individuals, families, and groups. The primary responsibility is to acquire a leadership role in the overall assessment, coordination and evaluation of innovative development programmes to meet the needs of the elderly and the community (Stanhope \& Lancaster, 2006).

Administrative skills as an administrator

As a health administrator the community health nurse may be responsible for the client and have direct and indirect authority and supervision over the organising staff and client care. They serve as decision makers and problem solvers.
Consulting skills as a consultant

The researcher acts as a consultant who involves problem solving with an individual, family or community to improve health care delivery. Fenton (1992) (in Hutti, 2005) identify the steps of the consultation process as: assessment of the problem, determining the availability and feasibility of resources, proposing solutions and assisting with implementation.

Researcher

The researcher can act as agent by conducting his/ her own investigations and answering questions relevant to nursing practice and primary health care (Polit \& Beck, 2008). Research in nursing practice can also improve nursing practice by the addition of new information to the existing body of scientific nursing knowledge. The researcher served as a change agent, working with individuals, groups, families and communities.

\subsubsection{Interpersonal relationships of the agent}

Developing a helping trusting relationship is the mode of communication that establishes a rapport of caring; the characteristics of caring are empathy and warmth.

Warmth means to accept the caregiver (Watson, 2005). Congruence means that the agent is genuine, honest and open in her/ his interaction with the caregiver. The agent requires patience, as recipients may process information at a slower rate than others. The agent needs to be helpful and supportive. Negative behaviour will prove to be futile. The researcher as a facilitator requires a high level of integrity to provide feedback on the results of the research and follow- through on promises.

She needs to have respect for the privacy and dignity of others, implying that if participants decide to withdraw from participating in the research, the researcher should respect this decision and not coerce or force participation. The agent needs to be nonjudgemental in order to work with persons of different creed, colour, race, ethnicity, sex, socioeconomic status or health status. The agent should allow freedom of expression without interference, as the lived experiences are unknown to her. 
The researcher, as a facilitator must have good interpersonal relationships and good communication skills, including good listening and probing skills. She should also possess excellent oral and writing skills so as to communicate easily, effectively and persuasively on the phone and in writing.

Qualities of the agent (researcher)

The three vital characteristics of a researcher are enthusiasm, perseverance and staying informed (Salloum, 2007). Caregivers and health workers are always surrounded by negative energy, as caring for the sick and the dying can influence enthusiasm. One deadly enemy in failing to demand all facts before committing ourselves to the venture is to sit, do nothing and lose it all (Michael, 2001). Hawker (2006) maintains that enthusiasm means excited interest in and enjoyment of something. Enthusiasm, according to Hornby (2006), means an excited or passionate interest or eagerness to do something. Michael (2001) says that an enthusiastic person exudes confidence in the working situation which is contagious. People with positive attitudes are always surrounded by positive energy. Positive people are always motivated and will find a solution for each difficulty (Weinstein, 2001). Michael (2001) states that enthusiasm in the way you smile, the way you walk and the way you act to attract others. According to Hill (2006), enthusiasm is fuelled by inspiration and perseverance, it travels with passion and its destination is excellence; powerful transformation takes place when we are surrounded by enthusiastic people.

In academic circles, rejection is rife, and part of this line of work; the key would be to regard this rejection as a learning opportunity and persevere against all odds. Perseverance, according to Hornby, (2006), means the quality of continuing to try to achieve a particular aim despite difficulties; to be steady and continue to act, usually over a long period, doing something in spite of difficulty or lack of success. According to Barrett, (2008) "perseverance" is to be committed and hardworking, to have patience and endurance, and be able to bear difficulties calmly and without complaint and to try again and again. People have the ability to display perseverance even though they come from a home where fighting and unhappiness is prevalent. Perseverance is to study and to work hard to give it try one's best, to obtain your ideals and never be a quitter.

The researcher should be creative and highly motivated; a good problem solver who sees problems as challenges that can be overcome. Hawker, (2006) explains "creative" as an adjective involving the use of imagination in order to create something. Motivation is explained in Hawker, (2006) as providing someone with a motive for doing something, i.e. making someone do something.

The researcher also needs to have a good appearance and be a good role model since they will represent their work place outside. They should be able to work as a member of a team and take direction.

Leadership

According to Clark (2003), leadership is the ability to influence the behaviour of others. According to Podolmy, Khurana and Hill - Popper (2005), leadership means the ability to lead, guide, direct or influence people. The researcher as a leader must be able to adapt her leadership style to fit the needs of the moment. As a leader, the researcher also has the function of identifying the need for action and leadership and assessing the needs of followers. According to Rick (2000), the point could be made that management and leadership are not the same, since persons who function like managers are not necessarily effective leaders. Today, strong leadership skills are more sought after than effective management skills. According to Milligan, (2006) a leader can be a motivator and cheer leader, setting the tone and nurturing morale, commitment and motivation.

A leader should be positive. A leader can also be the promoter and makes plans to increase success in each role of the followers (Leadership and dealing with conflict 2010).

There are seven good leadership principles that will produce the desired respect and trust in followers (Leadership and dealing with conflict, 2010).
- Leaders should be competent in their job. It is the duty of a leader to ensure continued professional development. The agent has the responsibility of being knowledgeable about principles of caregiving and to discern the level of knowledge to be disseminated to caregivers, who are often unqualified. Latest best available evidence should be employed to ensure evidence-based practice, even at the level of caregivers.

- Leaders should know their people and know themselves. Leaders cannot lead if their followers do not know them. Interaction with those under the agent's leadership is essential. Being involved as a cheer leader and motivator best describes a leader, as stated by Milligan (2006). The agent should know the strengths and weaknesses of those he/she works with. Accordingly, a situational analysis made it possible to investigate the strengths and weaknesses of caregivers. The agent as a professional nurse and lecturer with extensive involvement in community work attained credibility as a leader.

- Leaders should be frank and keep subordinates well informed. The agent should be honest and disclose the strengths and weaknesses of the caregivers. Work done well should be praised. Accordingly, after the completion of phase one, when the data had been analysed, the caregivers were informed of the outcome of the data analysis, especially with regard to the general experiences of the elderly. As the elderly receive services from the caregivers, the input of the elderly gave an indication of the quality of care given.

- Leaders should aim to be good coaches, set realistic standards and give an indication of reasons for standards of practice. As mentioned previously, the agent had to be able to discern the level of the knowledge to be disseminated to the caregivers, as this would ensure the establishment of realistic standards. The agent had to be a good instructor and explain and demonstrate procedures step by step. Caregivers were given the opportunity to practise or demonstrate what they learnt so that uncertainties could be clarified. An important reason for maintaining standards of caregiving is the safety of the elderly and to prevent medico-legal hazards.

- Leaders need to be impartial and avoid favouritism. (Nobody likes everybody in this world). An essential part of the educational programme was to inform caregivers of the characteristics of ageing, as well as the dynamics of intrapersonal functioning, which established a basis for caregivers to understand and accept the physical, psychological and social changes in the elderly. In this way, the caregivers would be able to cope with the change in behaviour of the elderly, which often leads to conflict, and would know how to handle it. The agent also needed to be objective and to understand the differing views of the caregivers.

- Leaders need to be sensitive. Sensitivity allows one to detect the subtle changes in individuals that indicate problems. The agent experienced very few difficulties with the caregivers, but sometimes willingness to participate was seen as an obstacle McNamara, (2010). The agent needed to be sensitive and observant and to respond quickly to problems with the caregivers. The humanistic value of sensitivity to one's self and to others is synonymous with recognising and sensing or feeling one's own feelings. The development of the self and the nurturing of judgement, taste, values and sensitivity in human relationships evolve from emotional states (Watson, 2006). In terms of this study, it was necessary to politely guide caregivers in the right direction. It was also very important to allow time between the sessions to discuss uncertainties and problems.

- Leaders need to be firm and be well rooted in what he/ she believes is right. A good leader will use all the information at his/ her disposal to make a decision. The agent, as a leader, must stand firm on his belief in what is right. Leaders often have this title, as they have relevant knowledge, skills 
and experience, which form a foundation on which to make relevant decisions, without being influenced by factors such as favouritism, friendships or a desire to avoid conflict. In this study, it was found that some caregivers with many years of experience in caregiving were reluctant to accept new information, but after being given reasons for the prescribed methods, they were able to concede that methods could change.

\subsubsection{Concluding remarks regarding the agent (facilitator)}

It is concluded that the agent as facilitator should possess the qualities, interpersonal relationship styles and leadership styles needed to successfully facilitate the participation of the recipients or caregivers of the elderly. Good leadership styles will produce the desired respect and trust between the facilitator and the recipient and ensure the development of competencies.

As described by Dickoff et al. (1968), the second aspect of activity in practice-oriented theory is the recipient. For this study the recipients are the caregivers at the five old age homes. Figure 4.3 illustrates the caregiver as the recipient.

Following will be a discussion on the recipient.

\subsubsection{Recipient: caregivers in old age homes}

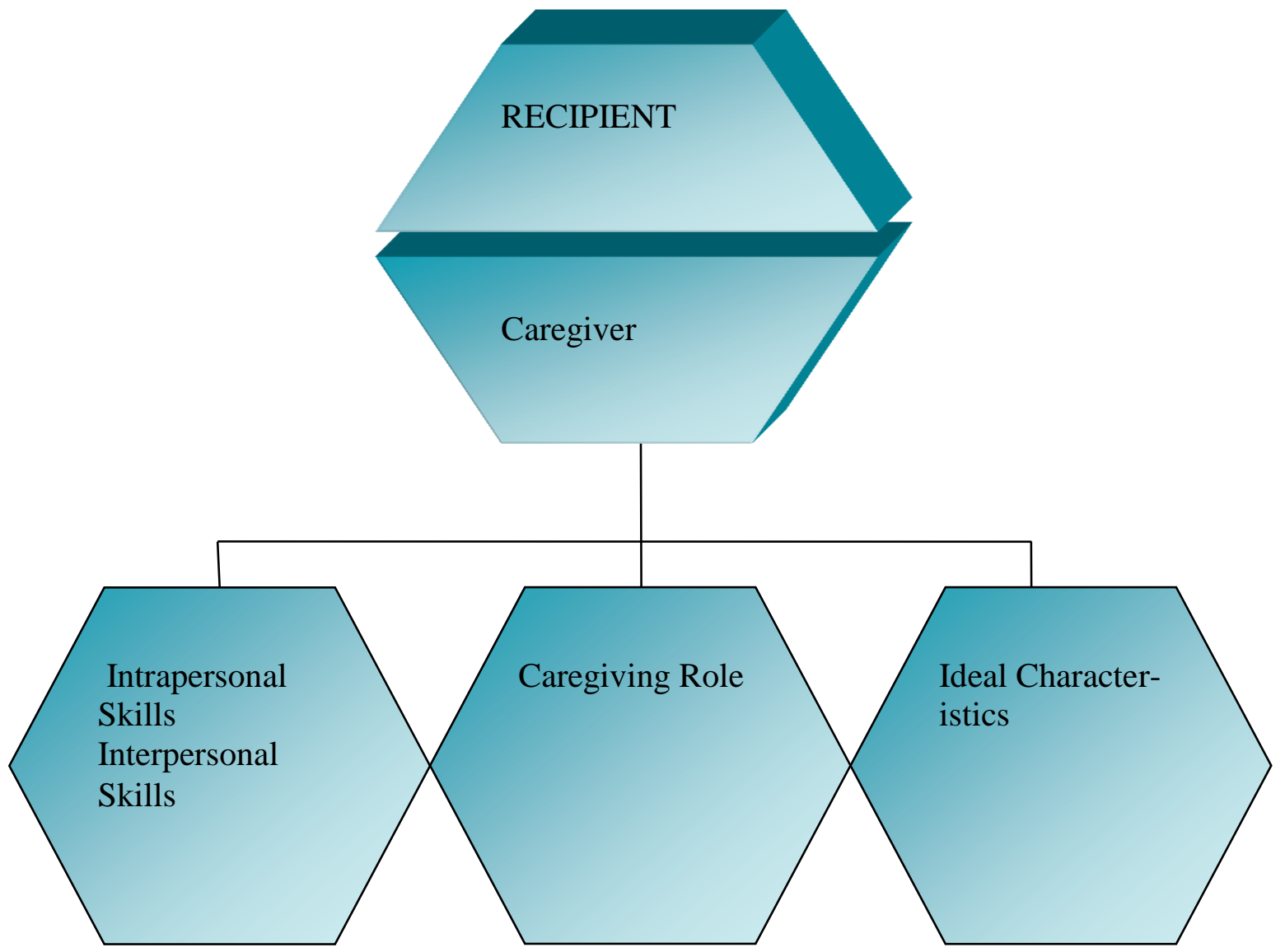

Fig. 2.1.4: Recipient: Caregiver in Old Age Homes.

According to the Hawker, (2006), the recipient (a common noun) is a person who receives something. In the study, the recipient was the caregiver who had the duty of caring for the elderly.

\subsubsection{Interpersonal skills}

Interpersonal skills are the skills that a person uses to interact with other people. These are sometimes referred to as "people skills" or "communication skills". Interpersonal skills involve using skills such as active listening and tone of voice, and also include delegation and leadership. They are about how well you communicate with someone or how well you carry yourself (Vincent, 2009). The ideal caregiver should have good interpersonal relationships and effective communication skills, should strive to be pleasant and be a good listener, owing to the fact that the elderly can be challenging to work with. The caregiver needs to be patient, as elderly people often suffer from hearing problems and instructions or messages often need to be repeated several times. Patience as quality for caregiving was mentioned by most of the caregivers, because they felt that the elderly are like children: you had to think for them; you had to remind them to wash, to dress and to eat. Consequently, short sentences should be used seeing that the elderly have memory problems. The caregiver needs to be motivated so that learning can take place.
Vincent (2009) states that the productivity of an organisation increases if positive skills are present. Some ways to improve interpersonal skills are the following:

- Think positively and enter a mind set to work well with others.

- Do not criticise others or yourself.

- Be patient.

- Learn to listen - experts recommend listening $80 \%$ of the time and only talking $20 \%$.

- Be sensitive to others.

- Treat others and their experiences with respect Mercury, (2006).

- Praise and compliment people when they deserve it.

- Look for solutions

- Do not complain.

Caregiving role

According to Hornby (2006), the term "clinical" is based on medical treatment or observation, practice or diagnosis. Hawker (2006) explains that clinical is related to the observation and treatment of patients.

The caregiver needs to know all the practical procedures needed to render a good service to the elderly. If these procedures are implemented, they will feel secure, their self-esteem will be high and 
every situation they face will be handled effective and with confidence (Dictionary.com Unabridged. (n.d.). 2011). the elderly need to be washed, dressed and groomed and require adequate mouth care, bed-making and intake and output. In some cases, caregivers are expected to wash used linen and clothes and also to clean rooms.

Watson's theory of carative factors provides a basis for a supportive, protective and corrective environment, as well as a sound mental, physical, socio-cultural and spiritual environment. For example, when the caregiver is dealing with a daily full wash or perineal care, he/she does it for restoring health Watson, (1979) (in Black \& Hawks, 2005). The carative factor teaches the caregiver that every human being has basic needs, that needs that are similar to Maslow's Hierarchy of Human Needs (1954). If caregivers deal with the daily routines, like full-wash and other procedures, a comfortable and safe environment is assured (Watson, 2005).

\subsubsection{Ideal caregiver characteristics}

Caregivers need to be innovative. The presence of competent caregiver's at old age homes must bring a change in the caring of the elderly. Hawker, (2006) states that "innovative "means to introduce and use new ideas or ways of doing things.

Caregivers need to be committed to their work. Committed means the caregiver must be willing to work hard and give her time and energy to her work (Hornby, 2006). During the inter-experiences, caregivers complained that there is no time for family life. If they are off duty they wonder whether the elderly people are ok. The elderly become like their children.

Caregivers need to be competent to do their work. Competence, according to Eksteen (1986) (in Muthuveloo, Rajendran, Rose, Raduan and Che, 2005) means to be qualified and able to execute patient care safely, without any medical hazards. According to the Hornby (2006), competence means having enough skills or knowledge to do well and to the necessary standard. This quality is important seeing that elderly people are a vulnerable group. Caregivers need to be gentle. According to the Hornby, (2005), gentleness means to be calm and kind, doing things in a quiet and careful way using a gentle voice/laugh/touch. Elderly people want to be treated with respect and to be talked to in a gentle way. If one is harsh they may not like you and will say that you have no manners. During the inter-experiences many of the elderly people complained that caregivers did not know how to talk to them.
Respect is another quality that caregivers need with regard to the elderly. Everyone has the right to be treated with respect Gorman, (2006). The elderly need to be respected in terms of their privacy and their possessions. Hornby (2006) maintains that respect means a feeling of admiration for someone because of their good qualities. Respect is a feeling or attitude of admiration and deference towards somebody or something.

Watson, (2006) investigated the issue of respect in five generations across Wales. The responses attained from the study distinguished respect as being a two-way process. Accordingly, respect given deserves respect in return. We live in a time where respect for one another is sadly lacking; self-interest with no consideration for others characterises our society.

According to the acurate and Reliable Dictionary (n.d.), punctuality means arriving or taking place at the arranged time, or the need to be punctual on duty. The dependent elderly need to receive their medicines, food and caring on time. According to an article in the Manila Bulletin (2006), punctuality is the trait of being on time in a meeting, in attending occasions, in doing one's work.

Punctuality connotes cooperation, considered tolerance, promptness, readiness, responsibility in attending to ones duties and obligations to others. Punctuality is a very important value that our caregivers must possess. In an article by Antonuk, (2007) quoting Dudycha (1937), it is maintained that men tend to be more punctual than women, but more women than men mentioned consideration for others as an important context of punctuality.

\subsubsection{Concluding remarks regarding the recipient}

The caregiver needs to have good interpersonal relationships in order to communicate effectively with the elderly, as well as with the facilitator. The ideal caregiver should be innovative, committed, competent, gentle and respectful, as well as punctual and responsible. To integrate these values the person must be at peace with him/herself.

The third activity in the practice-oriented theory described by Dickoff et al. (1968) is the context. In this study, the context is the old age homes where the caregivers work.

Figure 4.4 illustrates the context, that is, the old age homes

\subsubsection{Context: old age homes}

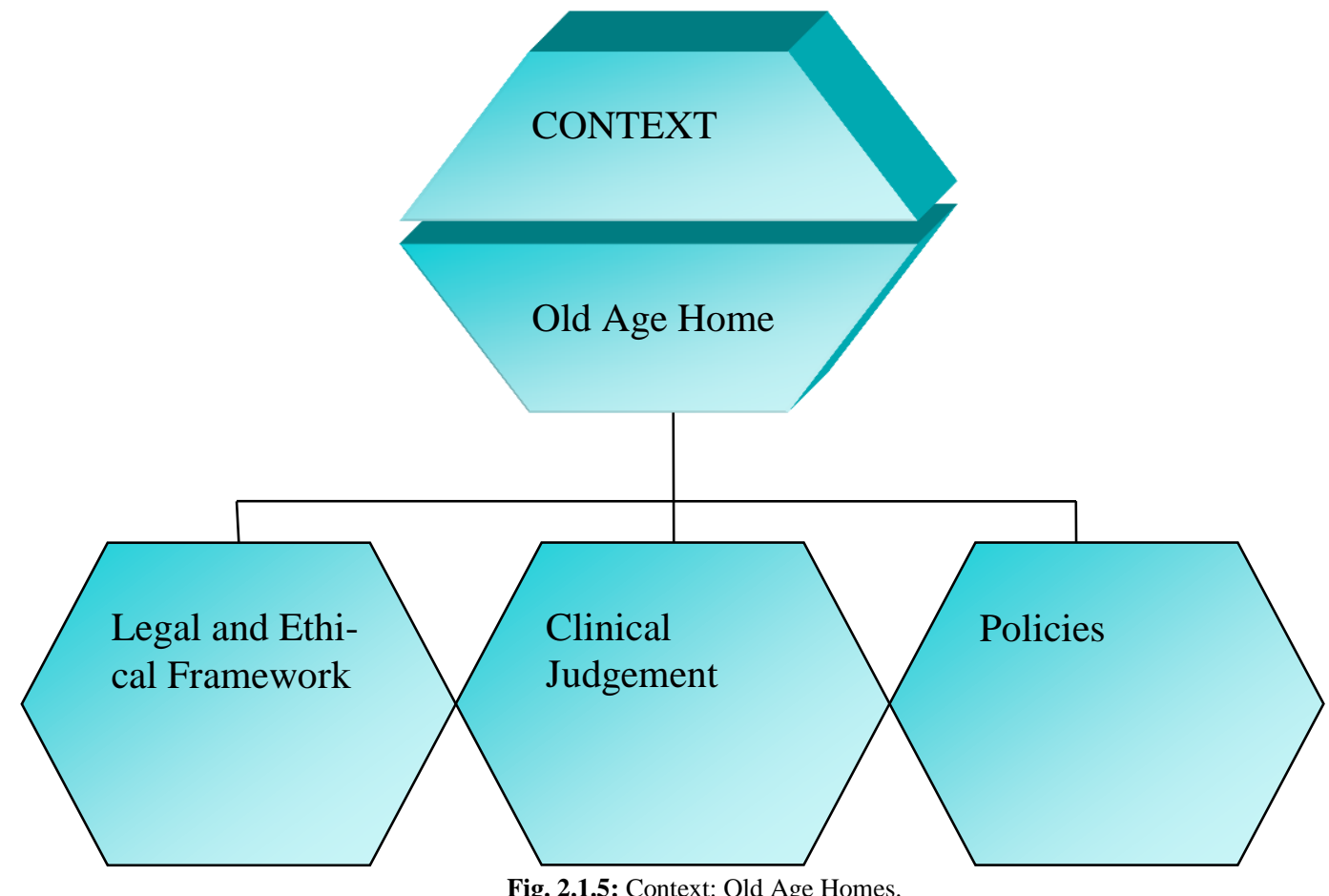

Fig. 2.1.5: Context: Old Age Homes. 
Hawker (2006) explains context as the circumstances surrounding an event, statement, or idea. In this case the old age homes are the context where the caring of the elderly took place. Old age homes have internal rules according to which they function. These concern the following: criteria for admitting an elderly person to the home; what the elderly have to pay for their board; visiting times for family and friends; what to do when elderly people are ill; safety aspect that have to be addressed when planning old age homes; elimination of environmental hazards; home and neighbourhood security; and prevention of elder abuse (Clarke, 2003). Watson (2009) divides the environment into physical safety and environmental factors. The aim of the caritas process is to create a healing environment on all levels, namely, physical, psychological, spiritual and social, to ensure comfort, peace and dignity.

\subsubsection{Legal and ethical framework}

Disciplinary code

Old age homes function according to a disciplinary code. On appointment, caregivers are given a copy of this code. On transgressing the code, the transgressor receives three written warnings. There after a labour consultant looks at the case and the defendant has the right to appeal any decision.

\subsubsection{Policies}

(a) Health and Safety Act (No 15 of 2004 in the Labour Act 1992 of 13 March 1992) cited in the Government .employees; to entrench fundamental labour rights and protection; to regulate basic terms and conditions of employment; to ensure the health, safety and welfare of employees; to protect employees from unfair labour practices; to regulate the registration of trade unions and employers' organisation to regulate collective labour regulations; to provide for the systematic prevention and resolution of labour despites; to establish a labour advisory council, a labour court, a wages commission and a labour inspectorate.

Regulations relating to the health and safety of employees at work (Government Notice No. 156 of 1997) are cited in the Government Gazette. This is just an overview of the different chapters protecting employers and employees:

Chapter 1: Rights and duties of employers. Employers need to know their rights and duties.

Chapter 2: Administration

Chapter 3: Welfare and facilities at workplaces

Chapter 4: Safety of machinery

Chapter 5: Hazardous substances

Chapter 6: Physical hazards and general provisions

Chapter 7: Medical examinations and emergency arrangements. Caregivers need to go for medical check-ups annually. They also need to attend their follow-ups for chronic diseases monthly Tanner, (2004).

Chapter 8: Construction safety

Chapter 9: Electrical safety

\subsubsection{2. (B) private health facility act 1999.2 commencement}

This Act is to amend The Hospitals and Health Facilities Act of 1994, so as to further regulate the Minister's powers with respect to the classification of state hospitals and state health facilities in terms of authorising the letting out of available rooms or space in a state hospital or state health facility for use for certain private purposes; to require that patients admitted for treatment at a state hospital or state health facility must elect to be classified as a state patient or as a private patient to further regulate the power of the Minister.
The Hospital and Health Facility Amendment Act, 1998 complies with a condition stipulated in the licence issued under subsection (3d) the owner of such a private health facility is convicted of an offence under this act by false information. The Minister can withdraw the licence. It is in the public interest to do so (Government Gazette of the Republic of Namibia 5 March 1998, Act no. 1804 of 1998).

\subsubsection{3. (C) aged persons act (act no. 81 of 1967) aged persons} amendment act no. 14 of 1971

To provide for the protection and welfare of certain aged and debilitated persons, for the care of their interests, and for the establishment and registration of certain institutions, for the accommodations and care of such persons in such institutions, for the payment of old age pensions and certain allowances to or in respect of certain aged persons (Statutes of the Republic of South Africa Salaries and Pensions 1967).

Namibia is still using the Aged Persons Act (Act No. 81 of 1967) of South Africa. Repeal of Ordinance 2 of 1965 of the territory of South West Africa in certain respects. (1) Subject to subsection (2), the Social Pensions Ordinance No. 2 of 1965), of the territory of Southwest Africa is hereby repealed in so far as it relates to old age pensions and matters incidental there to.

\subsubsection{4. (D) living will}

Owing to advances in science and technology to extend life and because of legal ethical issues related to dying, more people provide their families with documents called advanced directives. Watson's factor on allowance for the existential- phenomenological spiritual dimension makes provision for life-death experiences and attending to the spiritual needs of the elderly (Watson, 2004).

Living wills are a legal document that specifies exactly what a person wishes at death. It generally states that no measures are to be taken to prolong life. A living will includes the following:

- Do not resuscitate in the case of cardiac or respiratory arrest.

- Do not hospitalise. Residents may choose to stay in old age homes although some procedures cannot be performed in nursing homes.

- Feeding restrictions - do not feed artificially.

- Medication restrictions - nonlife-sustaining medication, antibiotics, chemotherapy, blood transfusions, surgery or tracheotomy.

All these instructions must be documented and witnessed by a lawyer (Hegner \& Acello \& Caldwell, 2009).

\subsubsection{Concluding remarks regarding the context}

The context in this study is the old age homes where caregivers are employed to render service to the elderly. To function properly they need to comply to certain conditions like health legislation in order to been issued with a licence to function, to provide a safe physical environment and to prevent medico-legal hazards to the elderly. It is also important for the management team to provide support and in-service training for the caregivers of the elderly. The fourth activity of the practice-oriented theory described by Dickoff et al. (1968) is the dynamics. For this study "dynamics" refers to the themes and sub-themes that were derived from the situational analyses of the interviews held with the elderly and the caregivers.

\subsection{Dynamics: interactive facilitation}




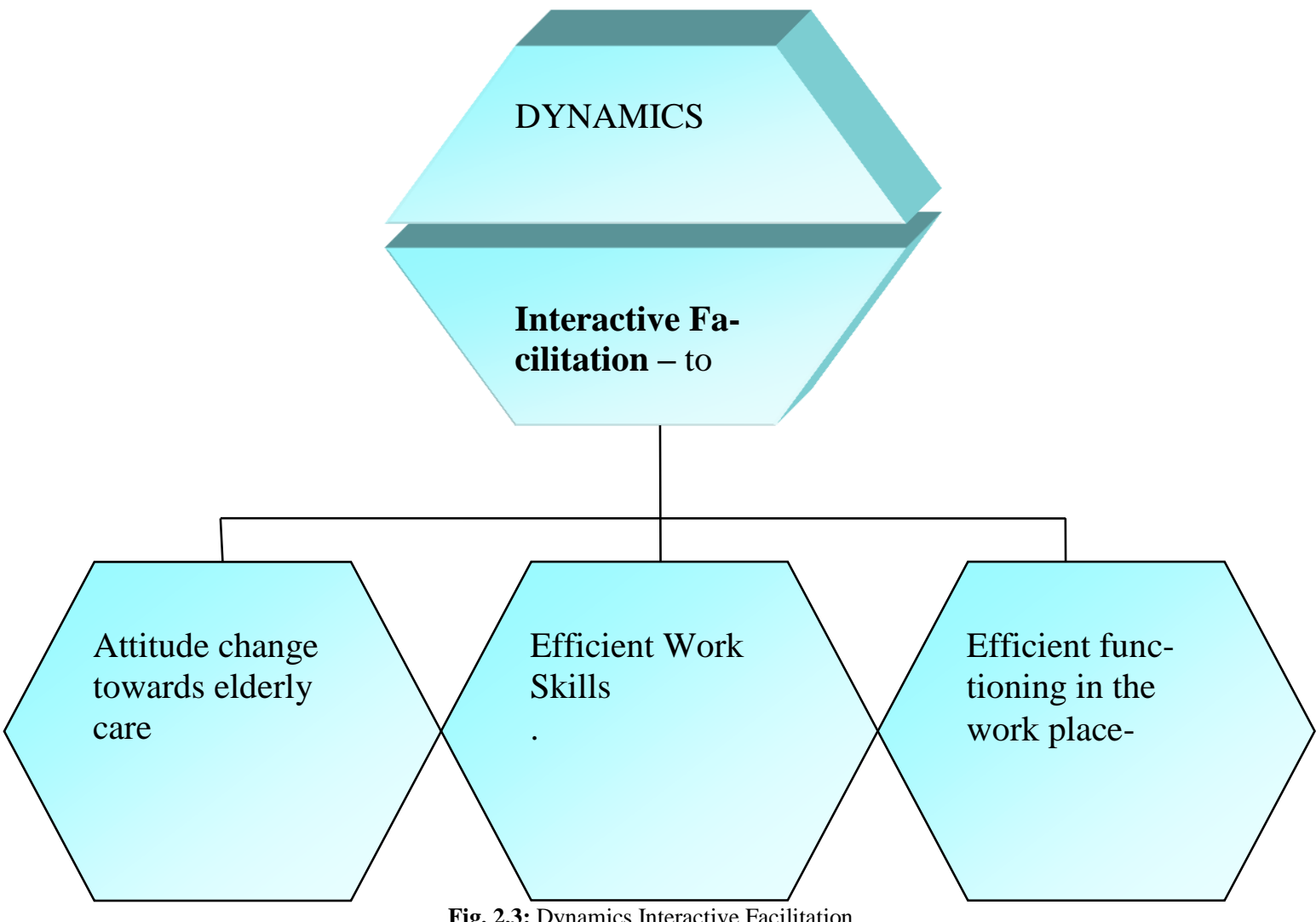

Fig. 2.3: Dynamics Interactive Facilitation.

\subsubsection{Attitude change towards elderly care is required}

According to the Hornby, (2006), "dynamics" means the forces involved in movement; forces which stimulate change, constantly changing and developing. It also means being full of energy, enthusiasm, and new ideas. Interactive means to influence each other and allowing a two-way flow of information between the caregiver and the user (Hornby, 2006). "Facilitation", on the other hand, means to make something possible and easier.

"Quality" means the standard of something as measured against other similar things. How good or how bad is the care given to the elderly? Excellence could be the highest or finest standard (Hawker, 2006). The focus of quality assurance is on making sure that the process by which care is provided meets certain established standards. If the standard is met, no action is warranted and programme operation moves and continue. Quality improvement focuses on the continuing improvement of educational programmes. The client's needs and expectations change over time, for example an elderly person's condition can change from independent functioning to total dependence. The programme needs to be adjusted to the circumstances in order to improve the care (Aday, Begley, Lairson \& Balkrishnan, 2004).

The researcher or manager might also contact clients or family members to obtain their perceptions of the quality of care provided to the elderly Cesta \& Tahan, (2002) (in Fitzpatric, 2006).

\subsubsection{Efficient work skills}

Hawker, (2006) states that the term "efficient" refers to working well, with no waste of money or effort.
The process of evaluation integrates efficiency, cost, equity, adequacy, quality, timelessness and satisfaction with the care receiver. Efficiency evaluation addresses the use of resources in relation to the outcome achieved by the programme. Programmes may be highly effective but may be delivered at a high cost (Linnan \& Steckler, 2002). What is the cost of the programme? Are resources (time, personnel, equipment and supplies, funding) being used as efficiently as possible.

\subsubsection{Elderly care programme as part of an educational sys- tem}

The development of an educational programme is like a plan of action to achieve something. This programme can contribute to the body of knowledge and can give caregivers a guideline for following the correct procedure.

\subsubsection{Concluding remarks regarding the dynamics}

In order to make the educational programme a success, there needs to be a good working relationship and cooperation between the caregiver and the facilitator.

The fifth activity of the practice-oriented theory described by Dickoff et al. (1996) is the procedures. For this study procedure refers to the educational programme for the elderly.

A discussion on procedure follows

\subsubsection{Procedure: educational programme}




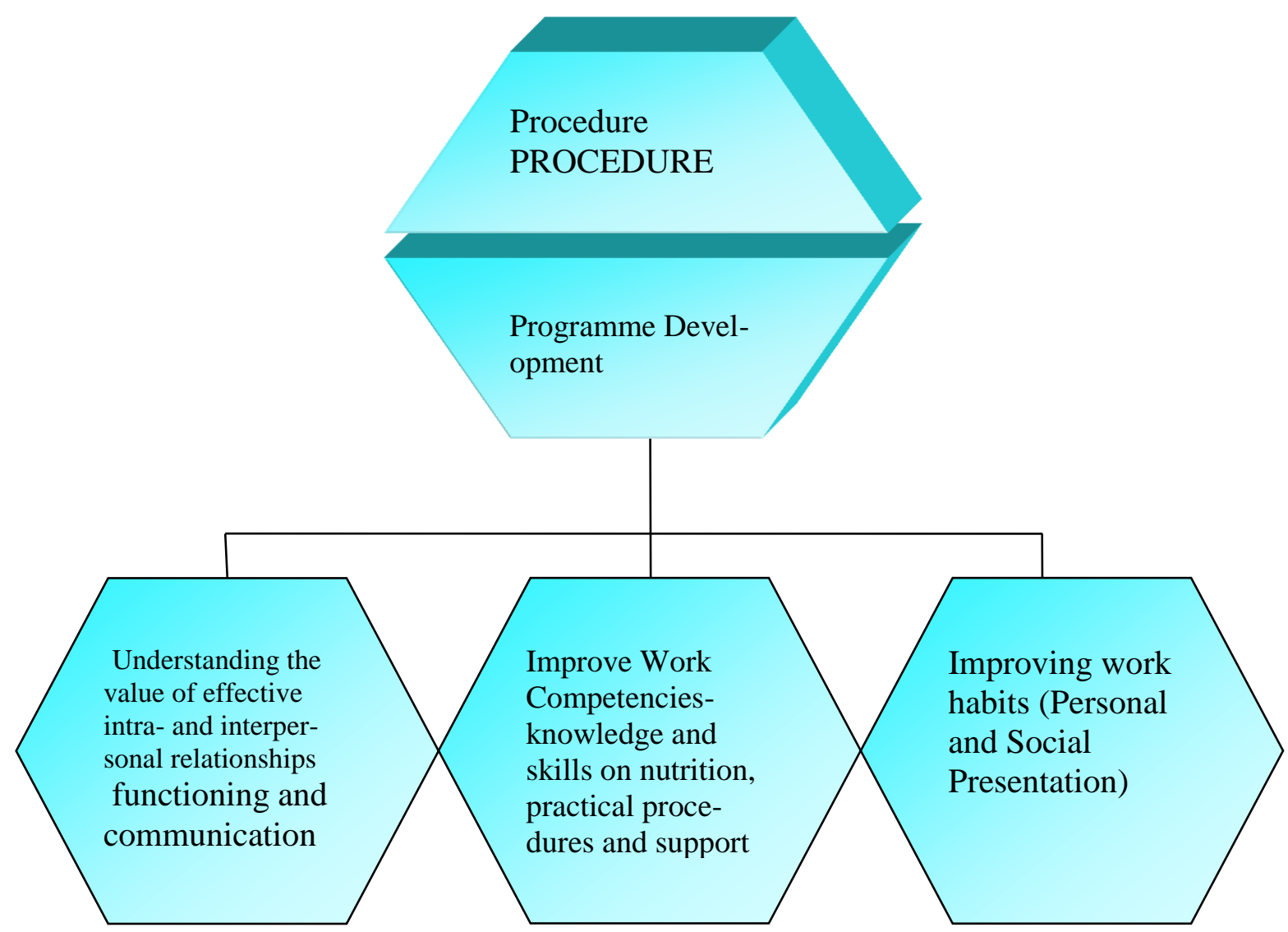

Fig. 4.6: Procedure: Educational programme.

The Hornby (2006) states that "procedure" means to establish an official way of doing something or a series of actions done in a certain way. Thesaurus (n, d) 2010 explains "procedure "as manner of proceeding; a way of performing or effecting something: A series of steps taken to accomplish an end.

The aim in developing a programme was to address the needs and shortcomings of the caregivers in order to improve the quality of care rendered to the elderly. The slogan for programme development is "Caring, prevention and efficiency through knowledge, skills and attitude".

In phase 1, a situational analysis was done using qualitative research. In-depth interviews were used to establish how the caregivers experience the caring that they render to elderly people and the elderly were asked how they experience the care that caregivers render to them. They were asked a simple question: "How do you experience the care that caregivers render to you?"

The concepts elicited were categorised into themes. Three themes were found.

\subsubsection{Understanding the value of effective intra- and interper- sonal relationships}

This was the first theme and it challenges caregivers with regard to negative and positive aspects. The sub-categories for this theme were emotions, communication, support and caring (Elderly Communication, 2010).

Although these were identified as interpersonal skills, it was necessary to address intrapersonal functioning as well. Watson, (2009) indicated that the human caring relationship is transpersonal in that it connotes a special kind of relationship, that is, a connection with the other person, a high regard for the whole person and their being in the world. We have different relationships with different people. Researchers say that interacting with a sales clerk in a store is different to interacting with friends and family members (Williams, Kemper, \& Hummert, 2004).
2.3.8. Improving work competencies, knowledge and skills on practical procedures and nutrition

Support and effective care for the elderly and educational sessions for caregivers comprised the second theme. Caregivers stated that they needed training in general procedures, for example, full wash, changing of linen and dressings and assessing vital signs and others.

\subsubsection{Improving work habits (personal and social presenta- tion)}

Caregivers voiced concern over the following aspects:

- Caregivers need support from management.

- There are shortages in human resources which influence their family life.

- There is no promotion for caregivers

- There is a lack of resources, such as transport, medicine and food.

- Caregivers also want a board that could carry out inspections and look after their interests.

These experiences are comparable to a lack of motivators and hygiene factors as described in Herzberg's Motivation-Hygiene Theory, (2002-2010). These factors affect job attitudes and have implications for management. The focus of the educational programme is on the development of skills for caregivers in order to promote quality care of the elderly. Herzberg's theory has implications for management, thus providing scope for further research or inclusion in the further development of the programme.

This theme focuses on improving work habits and social skills in the workplace and can be considered as an attempt to enable caregivers to improve their level of esteem concerning the totality of their work performance.

Caring

Caring is the basis for looking after the elderly people. The Encarta Dictionary (n.d.) explains "caring" as being compassionate or showing concern for others. Caring is also related to professions 
that involve looking after people's physical, medical, or general welfare, for example nursing. Leininger (1990) (in Seaton, 2010) predicts that, by the year 2010, "the central and major focus will be on caring and legitimising the discipline and profession of nursing care." Consumers will seek caring behaviours, decisions, and actions that show respect for human beings Leininger, (1990) (in Seaton, 2010). Caring is grounded on a set of universal humanistic altruistic values, the basis of which is to ensure human caring and promote the best care. In a caring science model for practice, all knowledge is valuable in accessing clinical caring (Watson, 2009).

\subsubsection{Concluding remarks regarding the procedure}

The development of the educational programme will ensure that caregivers will understand themselves and be able to form good interpersonal relationships with the elderly, as well as with coworkers and with their own families.

The sixth aspect of the practice-oriented theory described by Dickoff et al. (1968) is the terminus. For this study, "terminus" refers to improvement of the quality of care of caregivers. A discussion on the terminus follows.

\subsection{Terminus: competent caregivers}

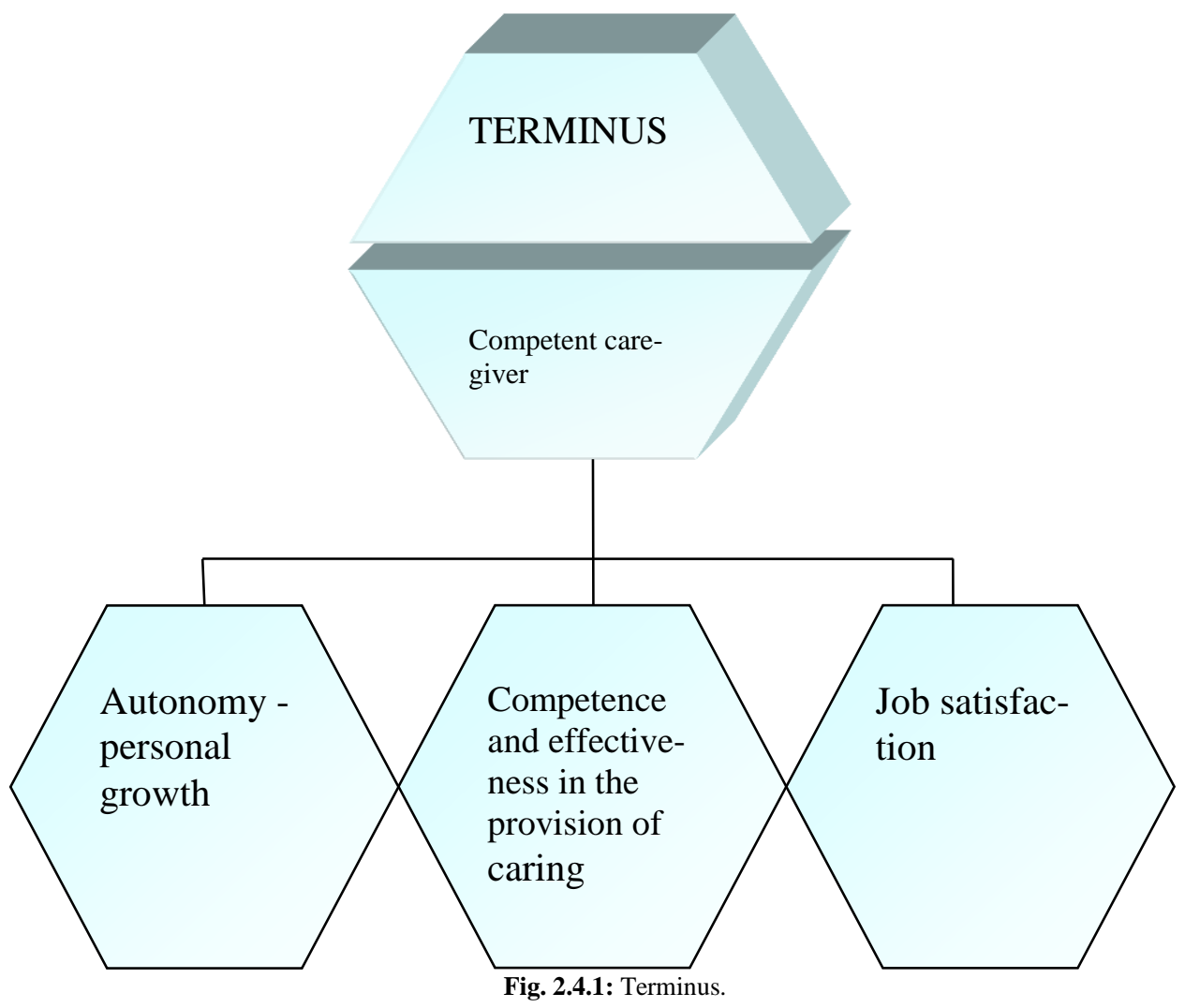

According to Hornby (2006), a terminus is a point where something stops or reaches its end. The aim of the programme is to uplift the standard of caring for caregivers in order to render better quality care for elderly people in old age homes. Caregivers need training in interpersonal skills; they need to know how to communicate with elderly people and what to expect from them. Owing to physical, psychological and social changes in the elderly, it is important for caregivers to know about these changes and how to handle them. Coffey, (1999- 2011) define competency as encompasses the skills, knowledge and abilities to practice caring for the elderly. Competencies develop over time and are measurable. Core competencies of caring include, knowledge, professionalism and ethics, leadership, communication, teamwork and collaboration, safety, quality improvement and evidence based practice.

\subsubsection{Autonomy - personal growth}

"Autonomy", according to the Miller-Keane Encyclopaedia and Dictionary (2003). (n.d), means self-government and political independence. The caregiver has to know how to make moral decisions and act on them. Autonomy or self-direction is a twofold attribute. Both the caregiver and the client tend to be more selfdirected in an institutional health care setting. Caregivers and the elderly need to have greater control over health care decisions than in other settings. They must then rely on their own decisions in choosing a course of action in consultation with other providers Rafael (1999) (in Chan, 2010). Autonomy is consistently associated with job satisfaction by several of authors (Leipert, 1996; Parahoo \& Barr, 1994 in Klijn, 2010); Reuter \& Ford, (1996) (in Klijn, 2010).

\subsubsection{Competence and effectiveness in the provision of caring}

Harvey (2004-2009), explains "competence" as the ability to do something well measured against a standard, especially ability acquired through experience or training.

The Dictionary.com. (n.d.) Explains "effectiveness" as producing, causing a result, especially the desired or intended result. In the case of the caregiver her/his work must be done excellently with the result that she/he makes a successful, favourable impression on co-workers, the elderly and their families.

\subsubsection{Job satisfaction}

A study on job satisfaction was conducted with 111 primary care workers. The results revealed that varied personality types chose occupations in the caregiving field. Satisfaction tended to be independent of personality type, but issues such as pay, promotion, and relationships with supervisors and co-workers were important 
variables in job satisfaction (Carter, (1988) (in Goliath service, 2004).

An exploratory study was conducted with twenty in-home caregivers of the elderly in the Boston, United States, area about the interaction caregivers have on the job that both enhances and hinders their job performance. This research sheds light on the structural difficulties such as low salaries, long working hours, and lack of job benefits (Scanlon, 2001). Caregivers are both physical and emotionally exhausted and wages remain low, with no opportunities for advancement. The job benefits are another discouraging factor and health coverage is scarce. Many who perform the work live near and below the poverty level (Scanlon, 2001).

Namibia is no exception - caregivers who were interviewed in this study complained that to care for the elderly is hard and difficult. It involves long working hours due to staff shortages, there is no time for family life, and no advancement or working benefits and the wages are very low. These are factors that influence job satisfaction in the caregiver.

\subsection{Conclusion}

This article describes the development of a conceptual framework. In order to do so the elements of Dickoff et al.'s

Agent

The agent is a researcher, who has developed an educational programme. The agent needs to apply all her scientific knowledge and experience to influence caregivers to change their behaviour and to provide better care for the elderly in old age homes.

Recipient

The recipient of the educational programmes the caregiver who works in the old age homes. The recipient/caregiver needs to be empowered with the content presented in the programme, namely intra- and interpersonal functioning, basic caregiving procedures, nutrition and basic work habits. This is intended to help them to solve problems experienced by the elderly people they care for. Caregivers need to demonstrate characteristics such as competency, gentleness, respect, honesty, and punctuality in taking care of elderly.

Context

The context in this study is the old age homes where the elderly are cared for and the caregivers are employed. Old age homes have their own administrative rules and regulations, and need to be legally approved by the Ministry of Health and Social Services to ensure a safe environment.

Procedure

The purpose of the educational programme is to produce competent caregivers who will be able to improve the quality care to the elderly and manage their problems. The programme procedure involves developing, implementing and evaluating the programme with the aim of improving the quality of caring for the elderly in old age homes.

Dynamics

Dynamics refers to the forces involved in bringing about change. The dynamics were derived from the situational analysis of the experiences of caregivers and the elderly, who allowed for increased insight into the specific difficulties experienced in caregiving for the elderly. Themes and sub-themes were formed from the data that were collected. The competencies of the agent and the dissemination of scientific-based knowledge about the way in which caregiving should ideally be performed provided the incentive for change.

Terminus

The terminus refers to the end point or the result that this programme must have. It refers to the implementing of the educational programme in old age homes in Windhoek and later in other old age homes in the Namibia. The terminus should include a change in the caregiver's attitude towards and relationship with the elderly.

Autonomy and personal growth are characteristics of both the caregiver and the elderly, who tend to be more self-directed in an institutional health care setting. Caregivers and the elderly need to have a greater control over their decisions made in a health care decisions than in other settings.

The competence involved in and the effectiveness of caring implies that caregivers should be skilled, qualified and experienced in their work environment.

Job satisfaction tends to be independent of personality type, and issues such as remuneration, promotion, and relationships with supervisors and co-workers have been identified as important variables in job satisfaction.

\section{References}

[1] Aday, L. A., Begley, C. E., Lairson, D. R., \& Balkrishnan, R. (2004). Evaluating the health care system: Effectiveness, efficiency and equity (3rd ed.).Chicago, IL: Health Administrative Press. Available online: http://www Medicinenet.com. Retrieved November $27,2010$.

[2] Accurate and Reliable Dictionary (n.d.). "Punctuality" Retrieved 20/06/11 A Free English - English online dictionary copyright $2004-2010$

[3] Aged Person Act (Act No 81 of 1967) Aged Persons Amendment Act no 14 of 1971 .

[4] Antonuk, B. (2007). The effect of temporal deadlines on the likelihood of engaging in anticipated and unanticipated goals. United States of America: ProQuest information and learning Company

[5] Barrett, J. (2008). Perseverance of the saints- Theopedia an encyclopaedia www.theopedia.com/Talk: Perseverance-of-the-saints.

[6] Black, M.J. \& Hawks, H.J. (2005). Medical and surgical nursing: clinical management for positive outcomes. St Louis, Missouri.

[7] Burns, N., \& Grove, S. K. (2005). The practice of nursing research: Conduct, critique \&utilization. (3rd ed.).London: W.B. Saunders.

[8] Carter, I. (2010). Caregivers window seat; Define a caregiver http://caregivers

[9] windowseat.blogspot.com2010definition.

[10] Chan, (2010). Customers Participation in value creation a double edged sword faculty. Fuqua.duke.edu/.../Chan\%20yim,\%20 and $\% 20 / \mathrm{am} \% 202010$

[11] Clarke, M. J. (2003). Community health nursing handbook. Norwalk, CT: Appleton \& Lange.

[12] Coffey, L. (1999-2011). Nursing competencies definition: eHow contributor.ehttp://www.ehow-com/facts-6949792-nursingcompetence

[13] Dictionary.com Unabridged. (n.d.). "Effective" Retrieved June 20, 2011, from

[14] Dictionary.com http://dictionary.reference.com/browse/effective

website:

[15] Dickoff, J., James, P., \& Wiedenbach, E. (1968). Theory in a practice discipline part 1: Practice orientated theory. American Journal of Nursing Company, 17(5), 438-488.

[16] Dzija, J., Hernandz, S., Nardi, S., Theriault, P. \& Wynne C. (2005). How to conduct effective focus groups and surveys: A project of adult education Strategic Plan:

[17] Elderly Communication. (2010) http://www.caring.com/article/

[18] Encarta dictionary: accessed (08/09/2009). Caring North America

[19] Fawcett, J. (1991). Approaches to knowledge development in nursing. Canadian Journal of Rogerian Nursing Research.7, 5-13

[20] Fawcett, J. (1999). The relationship of theory and research. Norwalk, CT: Appleton-Century-Crofts

[21] Fitzpatrick, J. J. (2006). Encyclopedia of nursing research. (2 ${ }^{\text {nd }}$ ed.) New York: Springer Publish Company

[22] Goliath service, (2004). Nursing home administration Level of job satisfaction/

[23] goliath.ecnext.com/.../gi.../Nursing home administration level-of htm

[24] Gorman, M. (2006). Development and the rights of older people. In J. Randel et al. (Eds), The ageing and development report: Poverty, independence and the world's older people. London: Earthscan.

[25] (Government Gazette of the Republic of Namibia 5 March 1998 Act no. 1804 of 1998). Private health facility Act of 1999.2

[26] Government Notice No 156 of 1997. No. 1617. (1997). Government Gazette of the Republic of Namibia: Regulations relating to the health and safety of employees at work. Labour Act, 1992 (Act No. 6 of 1992).

[27] Harvey, L. (2004-2009). Analytic Quality Glossry, Quality Research http://www.qualityresearchinternational.com/glaossary/

[28] Hawker, S. (2006). Little Oxford English dictionary (9th ed.).Oxford: Oxford University Press. 
[29] Health and Safety Act (No 15 of 2004 in the Labour Act 1992 of 13 March 1992) cited in the Government Gazette (2004)

[30] Hegner, B. R., Acello, B., \& Caldwell, M. A. (2009). Nursing assistant: A nursing process approaches-Basics. United States of America: Delmar.

[31] Herzberg's Motivation Hygiene Theory (Twofactor Theory) Internet Center for Management and business Administration, Inc (2002-2010). Herzberg-Motivation-Hygiene Theory http://www.netmba-com/mgmt/do/motivation/herzberg/

[32] Hill, R. (2006). Interpersonal Compatibility and Workgroup Performance, 11(2). The journal of applied behavioural science 2 ( 11: $210 \quad-\quad 219$ : Available online at: http:deepblue.lib.umich.sdu/bitstream/2027

[33] Hornby, A.S. (2006). Advanced Oxford Dictionary. $7^{\text {th }}$ (Ed.). Oxford University Press Inc New York

[34] Hutti, M. (2005). National Organisation of nurse practitioner faculties NONPF), 1993-2005; Southern Nursing research society (SNRS) - charter member, 1986-present... Louisville.edu/ nursing/ .../dr-marianne -hutti-dns - whnp -bc

[35] Klijn, M. (2010). A review of creativity within organizations from psychological..... http://dx.doi.org/10.1108/02621711011039141.

[36] Dspace.ou.nl/.../...

[37] Leadership and dealing with conflict (2010) Available online at: http:www.nsba.org/sbot/toolkit/Conflict.html

[38] Linnan, L., \& Steckler, A. (2002). Process evaluation for public health intervention and research: An overview. San Francisco, CA: Jossey-Bass

[39] Maslow, A. H. (1954). Motivation and personality. New York, NY: Harper

[40] Masunga, S.H. (2007). Research design and data analysis: upetd.up.ac.za/thesis/

[41] Manila Bulletin (2006). Punctuality week. (Opinion \&editorial.htt//www. High

[42] beam. Com/doc/1G1-144300146, html

[43] McNamara, C. (2010). All about leadership. Free Management Library Available online at http://managementhelp.org/1drship/idrship.htm\#anchor293932

[44] Michael, D. (2001). The power of enthusiasm. Business Magazines. Available online at: http://www,highbeam,com/doc/igi71006115.html

[45] Miller-Keane Encyclopaedia and Dictionary (2003), Autonomy of Medicine, Nursing, and Allied Health, Seventh Edition. Saunders, an imprint of Elsevier, Inc [Accessed July 2011].

[46] Milligan, B. O. (2006). Understanding Leadership roles and Leadership styles. [Online] available fromwwwalearningEdge.com [Accessed Oct 2008

[47] Mouton, J. (1996). Understanding social research. Pretoria: Van Schaik.

[48] Muthuveloo, Rajendran, Rose, Raduan, Che. (2005). Article: Typology of organisational commitment. American Journal of applied sciences, June 12005 Available online at http://www.highbeam.com/doc/1G1-145683323.html.

[49] Norlyk, A. (2010). What makes a phenomenological study: Phenomenological qhr.sagepub.com/content/20/3420? Full pdf

[50] Polit, D. F., \& Beck, C. T. (2008). Nursing research: generating and assessing evidence for 8th ed. London: Lippencott

[51] Rick, L. (2000). Leadership: Critical managers. Prima's North American papermaker. Available online at: http:www, highbeam.com/doc/1G1-69391629,html.Highbeam research.

[52] Salloum, I. M. (2007). Excerpt from interview with researcher at the 2007 International Conference on Bipolar Disorder in Pittsburgh: PA. http:www.4researcers.org/articles/1985.

[53] Seaton, L. (2010). Culture in nursing: A critical analysis.utsescholarship.lib.uts.edu.

[54] Au/dspace (bitstream/.../02whole.pdf? 4.

[55] Stanhope, M., \& Lancaster, J. (2006). Foundations of nursing in the community: Community-oriented practice. St Louis, MO: Mosby.

[56] Scanlon, M. (2001). Negotiating blurred boundaries: An analysis of caregiving work from perspectives of in home caregivers. http://wwwallacademics.commeta/pmla-apa- researchcitation1/0/9/5/3pages $104537-3 \mathrm{php}$.

[57] Tanner, E. (2004). Chronic illness demands for self-management in $\begin{array}{llll}\text { older adults. } & \text { Geriatric Nursing, }\end{array}$ http://dx.doi.org/10.1016/j.gerinurse.2004.08.003.

[58] Tesch, R. (1995). Qualitative research: Analysis types and software tools.New York Falmer

[59] Thesaurus Dictionary (nd). (Accessed November 2010). Procedure. From http://www http://www.google.com.na/search?Q
[60] Vincent, B. (2009). The three different levels of listening. (http://communicatebetter.blogspot.com/Three-different-levels-oflistening.html.

[61] Watson, J. (2004). Epilogue on home health nursing. In R. Rice (Ed.) Home care nursing: Practice and concepts (4th ed.). St Louis: Elsevier.

[62] Watson, J. (2005). Caring science as sacred science. Philadelphia, USA: FA Davis.

[63] Watson, J. (2006). Theory of human caring. (acesso em 2006 Nov 11). Disponivel em:http://www.uchsc.edu/nursing/caring

[64] Watson, J. (2009). Theory of nursing. Available online at: http://currentnursing.com/nursing_theory/Watson/html.

[65] Weinstein, E. (2001). What is internal motivation? LASSI instructional modules. Retrieved November 29, 2010, from file://www.hhpublishing.com/-onlinecourses/studystrategies/BSL/Motivation/H5.html

[66] Williams, A., Kemper, S., \& Hummert, M. L. (2004). Enhancing communication with older adults: Overcoming elder speaks. Journal of Gerontological Nursing, 30(10). http://dx.doi.org/10.3928/0098-9134-20041001-08.

[67] Woodgate, R. L. (1999). Conceptual understanding of resilence in the adolescent with Cancer. Part 1. Journal of Pediatric Oncology. 